American Journal of Economics and Business Administration 3 (1): 165-170, 2011

ISSN 1945-5488

(C) 2010 Science Publications

\title{
Involvement of Service Knowledge Management System in Integration of ITIL V3 and Enterprise Architecture
}

\author{
Akbar Nabiollahi, Rose Alinda Alias and Shamsul Sahibuddin \\ Faculty of Computer Science and Information Systems, University Technology Malaysia, \\ 81310, UTM, Skudai, Johor, Malaysia
}

\begin{abstract}
Problem statement: This study attempts to investigate and clarify the relationship of Service Knowledge Management System (SKMS) with our primary study regard to using enterprise architecture through ITIL V3. Approach: SKMS concepts are introduced by ITIL V3 as a set of tools and databases that are used to manage knowledge and information of IT services. Results: The SKMS stores, retrieves, updates and presents all information that is expected for management of whole lifecycle of IT Services. Primary goal of our research is to provide a comprehensive integrated framework to determine and address IT Service Architecture requirements and related issues in ITIL V3 through using Enterprise Architecture. Conclusion/Recommendations: Through the main process of our study we realized that ITIL Knowledge Management process and its model for SKMS might be good candidates for storing and retrieving architectures of IT services. In other word, SKMS can be used as a set of tools and databases for management of architecture components of our target framework. For next step, the concern is how to develop proposed SKMS.
\end{abstract}

Key words: IT Service Management (ITSM), knowledge management, Enterprise Architecture (EA), Service Design (SD), Service Oriented Architecture (SOA)

\section{INTRODUCTION}

IT Service Management (ITSM) was established based on modern international standards such as ISO/IEC 20000 and ITIL. There is a need for research that investigates the economic and social outcomes of ITSM as it relates to globalization of IT services and workforce (Galup et al., 2007). ITIL is an important and influential center of gravity in IT management (Betz, 2006).

ITIL V2 has been introduced in mid 90s and it was only focused on Service Delivery and Service Support and IT providers realized that there is a lack in strategy and design of service in practice. In 2007, OGC has released ITIL V3 to cover whole lifecycle of service which included five volumes as five stages of service: Service strategy, Service Design, Service Transition, Service operation and Continual Service Improvement (OGC, 2007). These publications only provide general guidelines on IT Service Management, thus each volume should be adapted and designed in details to be used in practice.

Knowledge Management is provided as a new process in ITIL V3 and is introduced in Service Transition volume. In this publication, ITIL defines Knowledge Management as the one central process responsible for providing knowledge to all IT Service Management processes. Within IT Service Management, Knowledge Management and Service Knowledge Management System (SKMS) are concerned with service knowledge. Underpinning this knowledge will be a considerable quantity of data, which will be held in a central logical repository or Configuration Management System (CMS) and Configuration Management Database (CMDB) (ITIL V3, 2007).

Research background: Today service is a general concept in many academic and practical disciplines. Each domain defines service in one way. It seems that these different definitions and applications of service term might cause some confuse in academia and practice. For instance, both SOA and ITSM are Service based but SOA usually is used in application development domain while ITSM recommends a service based management system (Gu and Lago, 2009; Voss and Hsuan 2009). It seems variety of service could cause some ambiguity in Service Sciences (Bardhan et al., 2010). As a suggestion by a researchers, Service could be considered as gravity center for Service Oriented Architecture, IT Service Management and recently Service Oriented Enterprise

Corresponding Author: Akbar Nabiollahi, Faculty of Computer Science and Information Systems,

University Technology Malaysia, 81310, UTM, Skudai, Johor, Malaysia Tel: 60147747402 
Architecture (Assmann and Engels, 2008) but it needs to be conceptualized or redefined. In other words, to convergence these various frameworks and standards, a service-oriented integrated framework is required.

\section{MATERIALS AND METHODS}

Demirkan et al. (2008) in study titled 'ServiceOriented technology and management: Perspectives on research and practice for the coming decade' have discussed on different aspects of service-oriented disciplines and have finally concluded that one of major challenges and issues of service sciences and industries that should be taken up by researchers and universities is the integration of technological and social science, management and policy research based on service(Demirkan et al., 2008). They also encouraged computer science, IS and management researchers to respond to conduct and develop multi disciplinary research efforts to begin to address that issue (Zhao et al., 2009). Moreover, they recommended various research paradigms and methods can be leveraged to investigate the challenging managerial and technical problems in service-oriented systems. Furthermore, they notified new researchers can use quantitative, qualitative and experiment methods, case and field studies and design science approaches (Demirkan et al., 2008).

Literature review, experiences of the authors and this demand have led us to the main question of study:

"How to converge IT service standards and frameworks through service-oriented integration of ITSM, EA and SOA to provide a common discipline and framework for service in research domains of computing, information systems and IS/IT management?”

Research objectives: The goal of this research is to develop a comprehensive integrated framework to identify and address IT Service Architecture requirements and issues through using Enterprise Architecture.

The research objectives that are defined based on this goal, research topic, problem statement and research questions are following:

- To define the roles of ITSM/ITIL and EA in IS/IT service delivery

- To identify architectural issues of IT Service Management.

- To design IT Service Architecture for ITSM and ITIL

- To develop a framework for integration of ITSM/ITIL and EA

It infrastructure library v3: As mentioned already, the ITIL Core books consist of five publications.
Service Strategy: The Service Strategy volume provides guidance on how to design, develop and implement service management. This guidance is provided on the principles covering the practice of service management that are useful for developing service management policies, guidelines and processes across the ITIL Service Lifecycle (Steinberg and Yearsley, 2007).

Service Design: The Service Design publication provides guidance on how to design and develop both services and service management processes. It also covers design principles and methods for converting strategic objectives into portfolios of services and service assets(ITIL V3, 2007).

Service Transition: The Service Transition volume provides guidance for development and improvement of capabilities for transitioning new and changed services into operations. This publication provides guidance on how the requirements of Service Strategy encoded in Service Design are effectively realized in Service Operation (Steinberg and Yearsley, 2007).

Service Operation: This volume embodies practices in the management of service operations. It includes guidance on achieving effectiveness and efficiency in the delivery and support of services so that to ensure value for the customer and the service provider(Office of Government Commerce, 2007).

Continual Service Improvement: This volume provides instrumental guidance in creating and maintaining value for customers through better design, introduction and operation of services. It combines principles, practices and methods from quality management, change management and capability improvement (Office of Government Commerce, 2007).

In Table 1 we summarized five stages (volumes) and all related process which each volume introduced for service lifecycle. The most important point hereby is that although each process is introduced in one stage, many of them are not limited to only one stage. For example process numbered c.7 as knowledge management affects on all stages except service strategy.

Service Design(SD) phase, as second phase of IT Service lifecycle in ITIL V3, all aspects of service design including: new or changed service solutions, service management systems and tools, technology architectures and management, systems processes, roles and capabilities, measurement methods and metrics should be considered(ITIL V3, 2007). One of these aspects is technology architecture of service which could be considered as the requirements of service 
Table 1: Summary of ITIL V3 stages and processes

ITIL V3 stages (volumes) and process

a. Service strategy

a.1 Service portfolio management

a.2 Financial management

a.3 Demand management

a.4 Strategy generation

b. Service design

b.1 Service level management

b.2 Cataloge management

b.3 Capacity management

b.4 Availability management

b.5 Service continuity management

b.6 Information security management

b.7 Supplier management

c. Service transition

c.1 Transition planning and support

c.2 Change management

c.3 Service asset and configuration management

c.4 Release and deployment management

c.5 Service validation and testing

c.6 Evaluation

c.7 Knowledge management

d. Service operation

d.1 Event management

d.2 Incident management

d.3 Request fullfilment

d.4 Problem management

d.5 Operation management

e. Continual service improvement

e.1 Service measurement

e.2 Service reporting

e.3 Service improvement

architecture. Service architecture attempts to integrate all information related to service. This information must involve applications, information, data and infrastructures for any IT service. These architectures are called Enterprise Architecture (ITIL V3, 2007).

Enterprise Architecture usually modeled as four architecture layers including business architecture, information architecture, application architecture and infrastructure architecture (Goikoetxea, 2007; Winter and Fischer, 2007; Aier et al., 2008; NIST, 2009) but not included service layer.

Service knowledge management process: The term knowledge is apparently consisting of data, information, intelligence, skill, experience, expertise, ideas, intuition, or insight in the context in which it is used. As often been mentioned, knowledge can be categorised into two types, which are Explicit Knowledge (EK) and Tacit Knowledge. EK is the knowledge that can be shared with others that can be documented, categorized transmitted to others (Tan, 2011).

\section{RESULTS AND DISCUSSION}

Knowledge management is defined as a systematic and integrative process of coordinating organizationwide activities of acquiring, creating, storing, sharing, diffusing, developing and deploying knowledge by individuals and groups in pursuit of major organizational goals (Stevens et al., 2010). Knowledge management is concerned with recognizing and managing all the organization's intellectual assets (which include knowledge, information and data) to meet business objectives (Fatt and Khin, 2010).

As mentioned above, Knowledge Management process is introduced through Service Transition volume of ITIL V3. The goal of Knowledge Management process in ITIL V3 is to enable organizations to improve the quality of management decision making by ensuring that reliable and secure information and data is available throughout the service lifecycle (ITIL V3, 2007). Knowledge Management is especially significant within Service Lifecycle since relevant and appropriate knowledge is one of the key service elements being used. During the service lifecycle an organization needs to focus on retrieving, sharing and utilizing their knowledge through problem solving, dynamic learning, strategic planning and decision making. To achieve this, knowledge needs to be transferred to other parts of the organization at specific points in the lifecycle. ITIL states that effective knowledge management is a powerful asset for people in all roles across all stages of the service lifecycle. It is an excellent method for individuals and teams to share data, information and knowledge about all facets of an IT service.

KMS is an IT system which is used to support and to strengthen the process of knowledge creation, access, transfer and usage. Knowledge management regards knowledge sharing as the core objective. Only through exchanges, can develop knowledge; only through the using of knowledge, can new knowledge be derived from the existed knowledge (Deng and $\mathrm{Hu}, 2007)$.

As Fig. 1 illustrated, Within IT Service Management, Knowledge Management could be formed within the Service Knowledge Management System (SKMS). Underpinning this knowledge will be a considerable quantity of data, which will be held in a central logical repository or Configuration Management System (CMS) and Configuration Management Database (CMDB).

SKMS for service architecture: As mentioned in section two, IITL defines its Service Knowledge Management System (SKMS) as following: “A set of tools and databases that are used to manage knowledge and information. The SKMS includes System Configuration Management System, as well as other tools and databases. The SKMS stores, manages, updates and presents all information that an IT Service provider needs to manage the full Lifecycle of IT Services.” (ITIL V3, 2007). 
Am. J. of Economics and Business Administration 3 (1): 165-170, 2011

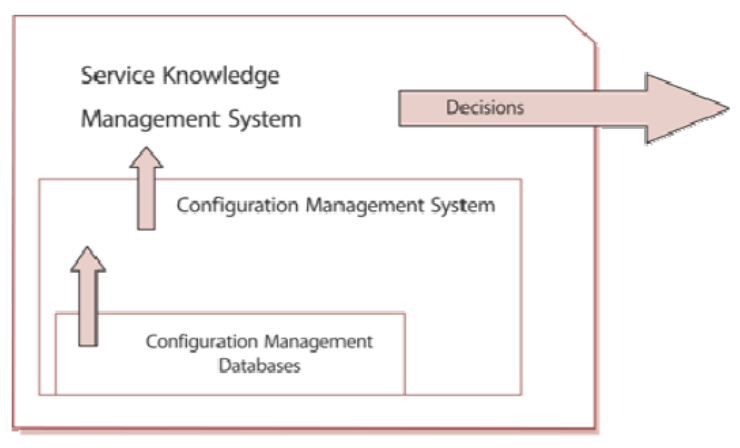

Fig. 1: Relationship of CMDB, CMS and SKMS(ITIL V3, 2007)

SKMS for service architecture: As mentioned in section two, IITL defines its Service Knowledge Management System (SKMS) as following: "A set of tools and databases that are used to manage knowledge and information. The SKMS includes System Configuration Management System, as well as other tools and databases. The SKMS stores, manages, updates and presents all information that an IT Service provider needs to manage the full Lifecycle of IT Services.” (ITIL V3, 2007).

In order to make effective use of data, in terms of delivering the required knowledge, an information architecture matched to the organizational situation and the knowledge requirements is essential(ITIL V3, 2007):

- Creating and regularly updating a Service Management information model

- Defining systems that optimize the use of the information while maintaining data and information integrity

- Adopting data classification schemes that are in use across the organization

When the requirements and architecture have been set up, data and information management to support Knowledge Management can be established. The key steps required involve setting up mechanisms to(ITIL V3, 2007):

- Identify the service lifecycle data and information to be collected

- Define the procedure required to maintain the data and information and make it available to those requiring it

- $\quad$ Store and retrieve

- Establish authority and responsibility for all required items of information
- Define and publicize rights, obligations and commitments regarding the retention of, transmission of and access to information and data items based on applicable requirements and protecting its security, integrity and consistency

- Identify the requirements to review, in the light of changing technology, organizational requirements, evolving policy and legislation

- Deal with collection and retention requirements

A service provider must first establish a service knowledge management system that can be shared, updated and used by its operating entities, partners and customers. Implementation of a service knowledge management system helps reduce the costs of maintaining and managing the services, both by increasing the efficiency of operational management procedures and by reducing the risks that arise from the lack of proper mechanisms.

Related literatures grouped the models of KMS into four types, which are knowledge type model, process management model, hierarchical model and knowledge chain model. A hierarchical service model can represent KMS architecture. From the perspective of service model, the framework of KMS can be divided into four levels or four layers. They are knowledge units, knowledge processing, knowledge storage and knowledge sharing (Deng and $\mathrm{Hu}$, 2007). ITIL suggests a four layer hierarchical model for SKMS including presentation layer, knowledge processing layer, Information integration layer and data and information sources and tools.

In ITIL V3, asset is defined as 'Any Resource or Capability'. Assets of a service provider including following types: Management, Organization, Process, Knowledge, People, Information, Applications, Infrastructure and Financial Capital, provided that could contribute to the delivery of a Service(Steinberg and Yearsley, 2007).

On the other hand, in the definition of Knowledge asset, ITIL states that 'Knowledge assets are accumulations of awareness, experience, information, insight and intellectual property that are associated with actions and context. Management, organization, process and applications assets use and store knowledge assets. People assets store tacit knowledge in the form of experience, skills and talent. Such knowledge is primarily acquired through experience, observation and training. Movement of teams and individuals is an effective way to transfer tacit knowledge within and across organizations. Knowledge assets in tacit form are hard for rivals to replicate but easy for owners to lose. Organizations seek to protect themselves from loss by 
codifying tacit knowledge into explicit forms such as knowledge embedded in process, applications and infrastructure assets.

Finally, ITIL in Service Transition volume clarifies that Knowledge assets include policies, plans, designs, configurations, architectures, process definitions, analytical methods, service definitions, analyses, reports and surveys.

To conclude, as mentioned in previous sections regard to integration of ITIL and EA, the main concern of the authors is the architectures of IT services, which could be considered as one of knowledge assets of IT providers. By refer to SKMS definition it is obvious that SKMS could be considered as a set of tools and databases for storing and retrieving IT service architectures. Therefore to provide a tool for target framework of the research, researchers will concentrate to design and develop a Service Knowledge Management System to support proposed target framework.

\section{CONCLUSION}

In this study, firstly ITIL V3 and its stages and processes were introduced briefly. Then some primary issues regard to main research has been mentioned. The main goal of researchers has stated as development of a comprehensive integrated framework to identify and address IT Service Architecture requirements and issues through using Enterprise Architecture”. We called this framework in our study as Integrated Service Architecture Framework (ISAF).

The research question related to this study is "How to fulfill architectural requirements of ITSM/ITIL by using Enterprise Architecture?” Also the research objectives which have led authors for analyzing service knowledge management system were the following:

- $\quad$ To design IT Service Architecture for ITSM and ITIL

- To develop a framework for integration of ITSM/ITIL and EA

We mentioned that special process as Knowledge Management is introduced in Service Transition volume of ITIL V3. The goal of this process in ITIL V3 is to enable organizations to improve the quality of management decision making by ensuring that reliable and secure information and data is available throughout the service lifecycle. Service Knowledge Management System (SKMS) is referred by ITIL V3 as a set of tools and databases that are used to manage knowledge and information.
The SKMS stores, manages, updates and presents all information that an IT Service provider needs to manage the full Lifecycle of IT Services. As we discovered in IT Service Management, knowledge assets includes policies, plans, designs, configurations, architectures, process definitions, analytical methods, service definitions, analyses, reports and surveys.

Through this study, we realized that regard to our main research problem, architectures of IT services can be stored and retrieved by SKMS. In other word, SKMS could be involved in study process as a set of tools and databases for storing and retrieving IT service architectures. Therefore researchers could plan to provide an automated tool for target framework through design and development of a Service Knowledge Management System.

\section{REFERENCES}

Aier, S., C. Riege and R. Winter, 2008. Unternehmensarchitektur-Literaturüberblick und Stand der Praxis. Wirtschaftsinformatik, 50: 292-304. DOI: 10.1365/s11576-008-0062-9

Bardhan, I.R., H. Demirkan, P.K. Kannan, R.J. Kauffman and R. Sougstad, 2010. An interdisciplinary perspective on IT services management and service science. J. Manage. Inform. Syst., 26: 13-64. DOI: 10.2753/MIS0742-1222260402

Demirkan, H., R. J.Kauffman, J.A. Vayghan, H.G. Fill and D. Karagiannis et al., 2008. Service-oriented technology and management: Perspectives on research and practice for the coming decade. Elec. Comm. Res. Appl. J., 7: 356-376. DOI: 10.1016/j.elerap.2008.07.002

Deng, Z. and X. Hu, 2007. Discussion on models and services of knowledge management system. Proceedings of the 1st IEEE International Symposium on Information Technologies and Applications in Education, Nov. 23-25, IEEE Xplore Press, Kunming, China, pp: 114-118. DOI: 10.1109/ISITAE.2007.4409249

Fatt, C.K. and E.W.S. Khin, 2010. The social-technical view of knowledge management in services industries. J. Soc. Sci., 6: 256-264. DOI: 10.3844/jssp.2010.256.264

Galup, S., J.J. Quan, R. Dattero and S. Conger, 2007. Information technology service management: An emerging area for academic research and pedagogical development. Proceedings of the 2007 ACM SIGMIS CPR Conference on Computer Personnel Research: The Global Information Technology Workforce, ACM, USA., pp: 46-52. DOI: $10.1145 / 1235000.1235010$ 
Goikoetxea, A., 2007. Enterprise Architectures and Digital Administration: Planning, Design and Assessment. 1st Edn., World Scientific Publishing, Singapore, ISBN-10: 9812700277, pp: 516.

Tan, C.N.L., 2011. Knowledge management acceptance: success factors amongst small and medium-size enterprises. Am. J. Econ. Bus. Admin., $\quad 3$ : 73-80. DOI: 10.3844/ajebasp.2011.73.80

NIST, 2009. NIST Enterprise Architecture Model. http://commons.wikimedia.org/wiki/File:NIST_Ent erprise_Architecture_Model.jpg

Office of Government Commerce, 2007. The Introduction to the ITIL Service Lifecycle. 1st Edn., The Stationery Office, London, ISBN-10: 0113310617, pp: 238.

ITIL V3, 2008. Information Technology Infrastructure Library Service Design. Procept Associates LtdPresentation for CIPS Toronto. http://www.slideshare.net/PROCEPT/itilv3service-design-presentation

Steinberg, R.A. and R. Yearsley, 2007. ITIL Design Guidelines: ITIL Service Strategy. Exclusive New Report. http://www.itiltrainingzone.com/pdfs/Itil_v3_servi ce_strategy_design_guidelines.pdf

ITIL V3, 2007. Service Transition. ITIL Portal. http://www.itilv3.net/Service-Transition.html

Gu, Q. and P. Lago, 2009. Exploring service-oriented system engineering challenges: A systematic literature review. Service Oriented Comput. Appli., 3: 171-188. DOI: 10.1007/s11761-009-0046-7
Assmann, M. and G. Engels, 2008. Transition to service-oriented enterprise architecture. Proceedings of the 2nd European Conference on Software Architecture, (ECSA' 08), SpringerVerlag, Berlin Heidelberg, pp: 346-349. DOI: 10.1007/978-3-540-88030-1_34

Stevens, R.H., J. Millage and S. Clark, 2010. Waves of knowledge management: The flow between explicit and tacit knowledge. Am. J. Econ. Bus. Admin., $\quad$ 2: 129-135. DOI: 10.3844/ajebasp.2010.129.135

Betz, C.T., 2006. Architecture and Patterns for IT Service Management, Resource Planning and Governance: Making Shoes for the Cobbler's Children. 1st Edn., Morgan Kaufmann, San Farncisco, ISBN-10: 0123705932, pp: 424.

Voss, C.A. and J. Hsuan, 2009. Service architecture and modularity. Decision Sci., 40: 541-569. DOI: $10.1111 / \mathrm{j} .1540-5915.2009 .00241 . x$

Winter, R. and R. Fischer, 2007. Essential layers, artifacts and dependencies of enterprise architecture. J. Enterprise Architecture, 3: 7-18.

Zhao, C., H. Gan and F. Gao, 2009. A study on the process model for IT service management. Proceedings of the 3rd WSEAS International Conference on Computer Engineering and Applications, (ICCEA' 09), World Scientific and Engineering Academy and Society, USA., pp: 206-210. 